\title{
Detachment rates of dreissenid mussels after boat hull-mediated overland dispersal
}

\author{
F. P. L. Collas - A. Y. Karatayev • L. E. Burlakova - R. S. E. W. Leuven
}

Received: 1 June 2016/Revised: 13 October 2016/Accepted: 6 December 2016/Published online: 23 December 2016

(C) The Author(s) 2016. This article is published with open access at Springerlink.com

\begin{abstract}
Introductions of the invasive zebra mussel (Dreissena polymorpha) and quagga mussel (Dreissena rostriformis bugensis) into hydrologically isolated water bodies have been attributed to overland transport via (recreational) boat hulls. Before a boat becomes a successful vector, mussels must (1) attach to the hull, (2) survive air exposure during overland transport and (3) establish a viable population either after detachment or release of spat during launching or sailing. This study mimics these dispersal barriers and assesses the potential of boat hull-mediated release into a recipient environment for both species. Individuals were allowed to attach to aluminium and fibreglass plates. Hereafter, attached individuals were
\end{abstract}

Guest editors: Manuel P. M. Lopes-Lima, Ronaldo G. Sousa, Lyuba E. Burlakova, Alexander Y. Karatayev \& Knut Mehler / Ecology and Conservation of Freshwater Bivalves

F. P. L. Collas · A. Y. Karatayev · L. E. Burlakova Great Lakes Center, SUNY Buffalo State, 1300 Elmwood St., Buffalo, NY 14222, USA

F. P. L. Collas $(\bowtie) \cdot$ R. S. E. W. Leuven

Department of Environmental Science, Institute for Water and Wetland Research, Radboud University, P.O. Box 9010, 6500 GL Nijmegen, The Netherlands e-mail: f.collas@science.ru.nl

R. S. E. W. Leuven

Netherlands Centre of Expertise on Exotic Species (NECE), Nature Plaza, P.O. Box 9010, 6500 GL Nijmegen,

The Netherlands exposed to air and subsequently submerged again. Zebra mussels had a significantly higher attachment rate than quagga mussels. The percentage of attached dreissenid mussels that detached alive during rewetting ranged between 7.9 and $21.8 \%$. No significant difference was found between species and hull materials. However, alive detachment during rewetting was significantly higher after $24 \mathrm{~h}$ compared to $48 \mathrm{~h}$ of air exposure. Our data allow modelling introduction pressure of lakes if quantitative data on overland boat movement and the density of attached mussels are available.

Keywords Quagga mussel · Zebra mussel · Fouling · Air exposure $\cdot$ Overland transport $\cdot$ Water craft

\section{Introduction}

The zebra mussel Dreissena polymorpha (Pallas, 1771) and quagga mussel Dreissena rostriformis bugensis Andrusov 1897 have successfully invaded and continue to spread in both Western Europe and North America, making it important to assess their vectors for spread. These mussels are able to attach to several other organisms and various types of substrate by producing byssal threads (Grutters et al., 2012). Biofouling by dreissenids threatens native mollusc species and causes negative economic effects (Pimentel et al, 2005; Karatayev et al., 2007; Ward and 
Ricciardi, 2007; Oreska \& Aldridge, 2011; Burlakova et al., 2014). Dispersal of dreissenids can be attributed to a wide range of vectors (Matthews et al, 2014). These vectors enable continued spread in an already colonized river basin as well as long-distance dispersal, including overland transport to isolated water bodies by water craft. In the case of the latter, recreational boats are among the main vectors (Buchan \& Padilla, 1999; De Ventura et al., 2016). Several authors report introductions due to ballast water exchange (Johnson \& Carlton 1996) and secondary spread due to discharge of water contained in boats (Johnson \& Carlton, 1996), macrophytes attached to anchors, propellers or boat trailers (Johnson \& Carlton, 1996; Johnson et al., 2001) or boat hulls (Minchin et al., 2003; Pollux et al, 2003).

Various dispersal barriers have to be crossed for successful overland transport via recreational boating. Mussels must be able (1) to attach to the boat hull (or other submerged parts such as an anchor, outboard motor or trailer), (2) to survive air exposure and prevent desiccation during overland transport and (3) establish a viable population either after detachment or release of spat during launching or sailing. The zebra and quagga mussel attach to a wide variety of materials (Ackerman et al., 1992, 1995; Marsden \& Lansky, 2000; Kobak, 2004; Mueting et al., 2010), including commonly used materials for the construction of boat hulls such as aluminium and fibreglass (Marsden \& Lansky, 2000; Mueting et al., 2010; De Ventura et al., 2016).

During overland transport zebra and quagga mussels can either detach or stay attached. Both species are capable of surviving several days of air exposure (McMahon et al., 1993; Ricciardi et al., 1995; Ussery \& McMahon, 1995; Tucker et al., 1997; Paukstis et al., 1999; Collas et al., 2014). Survival depends on the air temperature and relative humidity (Ricciardi et al., 1995).

After the overland transport mussels have to detach from the boat hull and reproduce in order to establish a viable population at the newly introduced site. Moreover, individuals that remain attached to a boat can potentially reproduce increasing the probability of establishing a viable population, though the boat has to remain in the same water for a prolonged period. Currently, information on the detachment rate after air exposure during overland transport is lacking. Numerous articles assess the detachment force needed to sever the byssal threads formed between dreissenids and substrates (Ackerman et al., 1992, 1995; Kobak \& Kakareko, 2009; Peyer et al., 2009; Kobak et al., 2010) or natural dreissenid detachment and movement (Kobak, 2001; Kobak et al., 2009). However, these studies do not consider the effect of preceding air exposure. The detachment force varies among substrates and depends on mussel size and species (Ackerman et al., 1992, 1995; Kobak \& Karareko, 2009; Kobak et al., 2010). Quagga mussels detach at a lower force than zebra mussels (Peyer et al., 2009).

Despite available information on several processes involved in boat hull dispersal pathways, quantitative data on assessments of the magnitude of zebra, and quagga mussel releases are scarce. This data is, however, essential for predicting dispersal probability considering the continuous range expansion of both dreissenid species in Europe and North America. We hypothesize that hull material and overland transport duration affects the magnitude of release into a recipient environment. Therefore, this study aims to assess (1) the attachment of adult mussels to two common types of boat hull material (fibreglass and aluminium) and (2) the effect of air exposure duration on alive detachment of dreissenids during rewetting.

\section{Materials and methods}

Mussel collection

Quagga and zebra mussels were collected in the Black Rock Canal at Squaw Island in Buffalo, NY $\left(42^{\circ} 54^{\prime} 46.5^{\prime \prime} \mathrm{N}, 78^{\circ} 54^{\prime} 09.2^{\prime \prime} \mathrm{W}\right)$. Only individuals with a length between 10 and $20 \mathrm{~mm}$ were used. All specimens were maintained for a maximum of 21 days in flow through aquaria filled with Black Rock Canal water at the Field Station laboratory of the Great Lakes Center SUNY Buffalo State, Buffalo (USA, NY).

Experimental setup

Two experiments were performed to mimic potential boat hull-mediated dispersal pathways of dreissenids (Fig. 1):

1. Attachment of mussels to common boat hull materials; 


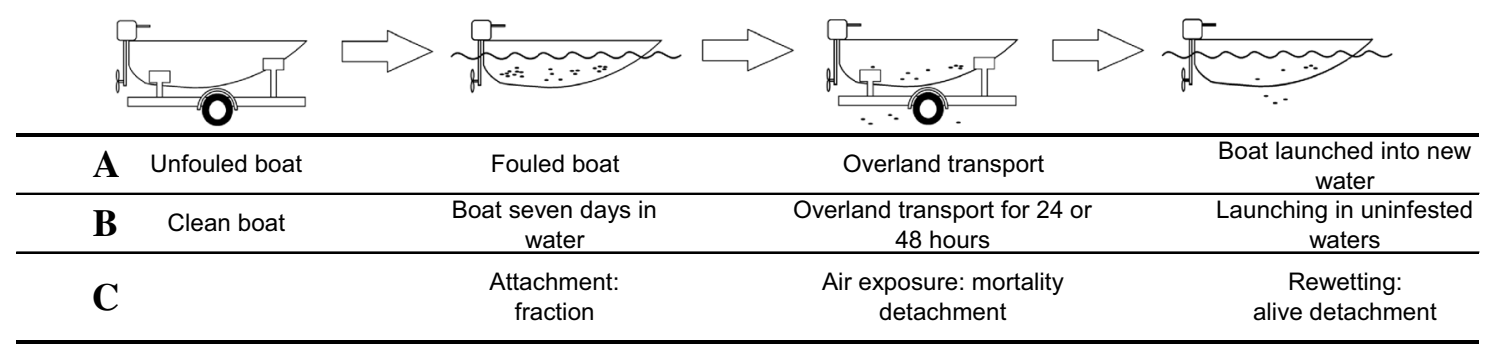

Fig. 1 Schematic overview of $A$ The general recreational boat hull-mediated dreissenid mussel introduction pathway, $B$ The experiment setup mimicked dispersal conditions without boat

2. Alive detachment during rewetting after air exposure.

\section{Attachment experiment}

Mussels were allowed to attach to either aluminium or fibreglass plates of $12.5 \times 20.0 \mathrm{~cm}$. Plates were placed in a double zinc-coated galvanized steel frame (mesh size: $6.2 \mathrm{~mm}$ ) with twenty-one evenly spaced cages on top of each plate (Fig. 2). Subsequently, at the start of the experiment, one mussel was placed inside each cage with its ventral side faced towards the substrate to stimulate attachment. The mussels were positioned within the cage leaning to the cage itself to aid with positioning their ventral side towards the substrate. After initial placement, individuals were not repositioned and left alone. Quagga mussel attachment experiments were performed with twenty-one individuals per plate, resulting in 1008 individuals for all

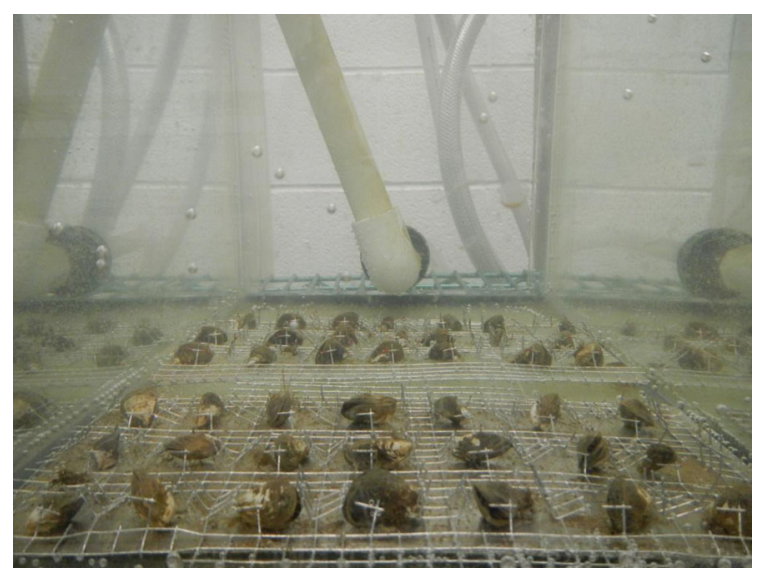

Fig. 2 A photo of a fibreglass and aluminium plate with a frame with cages with dreissenid mussels cleaning and $C$ Factors determining the probability of mussel introductions via boat hulls

48 plates. Due to limited availability of zebra mussels, ten individuals of this species were used per plate, resulting in 480 individuals on 48 plates. Hereafter, one random aluminium and one random fibreglass plate with frames were placed at the bottom of a random aquarium, 48 in total. Aquaria were then filled with temperature-controlled water of the Black Rock Canal via a flow through system $\left(>101 \mathrm{~h}^{-1}\right)$. A sevenday attachment period was used since after this period attachment strength of dreissenid mussels does not further increase (Kobak, 2013). During this period, plates were not cleaned resulting in the development of a biofilm that facilitates attachment (Kavouras \& Maki, 2003). The water temperature during the sevenday attachment period ranged between 20.8 and $21.2^{\circ} \mathrm{C}$. After seven days, the mesh and water were removed. Individuals were considered attached if they remained attached after the plate was turned upside down. All individuals that did not attach to a plate were removed.

\section{Rewetting after air exposure}

The plates acquired from the attachment experiment were subsequently exposed to air for a certain period. Subsequently, an assessment was made of alive detachment after rewetting (Fig. 1). Overall 36 different aquaria were used for the experiment. To each aquarium at random, either three aluminium plates or three fibreglass plates with the same species attached were assigned. Moreover, within each aquarium, the three plates were randomly positioned vertically, horizontally and in a $45^{\circ}$ angle, resembling all different shapes of a boat hull. Since plates of the attachment experiment were used, varying individuals were attached to each plate, ranging between three and 
eighteen individuals for quagga and four and ten individuals for zebra mussel colonized plates. In total, 498 and 354 individuals were used for quagga and zebra mussels, respectively. Plates were exposed to air with a humidity of $82 \%$ for 24 or $48 \mathrm{~h}$ at 21.2 and $21.4^{\circ} \mathrm{C}$, respectively. After either 24 or $48 \mathrm{~h}$ of air exposure aquaria were rewetted, thereby mimicking the launching of a boat into a new water body. At these points in time, all plates were immersed in water, ranging in temperature between 22.3 and $22.7^{\circ} \mathrm{C}$. Finally, all individuals that detached were collected after 24 and $48 \mathrm{~h}$ and immersed again in a separate container to ascertain whether the specimen was alive or dead. Specimens floating directly after immersion were submerged with tweezers, thereby releasing air from the shells. After $24 \mathrm{~h}$ of immersion, specimens were classified as dead when stimulation of the mantle did not result in shell muscle contraction (Paukstis et al., 1999). Dead individuals were additionally checked after $48 \mathrm{~h}$ of immersion. Individuals that remained attached after rewetting were also checked for survival.

\section{Data analyses}

A binomial generalized linear model (GLM) was used to analyse the fixed effect of species, air exposure duration and material type on the fraction of (1) attached individuals and (2) alive detached individuals during rewetting of the attached individuals. Nesting effect of aquarium was not included as all plates were randomly assigned to the aquaria throughout both experiments. Moreover, temperature conditions were similar between all aquaria throughout the experiment. The analyses were performed using the GLM function in R statistics (R Development Core Team, 2008). Due to different experimental conditions, analyses were carried out separately per experiment. Model selection was based on the lowest Akaike's information criterion (AIC) value in combination with testing for a significant model improvement of which the latter was decisive. Significant model improvement was analysed using the difference in deviance between the two models, which is Chi-square distributed. Subsequently, the $P$ value was calculated using the difference in deviance and the corresponding degrees of freedom. Models that only included main effects were the best performing ones (Table 1).

\section{Results}

Attachment

The average mussel attachment during the experiment was $49.4 \pm 17.4 \%$ (SD) and $73.8 \pm 14.8 \%$ (SD) for the quagga and zebra mussel, respectively. The proportion of zebra mussel attachment was significantly higher than quagga mussel attachment ( $z-$ value $=8.80, P<0.001)$. Additionally, fibreglass attachment was significantly higher than aluminium attachment $(z$-value $=6.00, P<0.001$; Fig. 3$)$.

Alive detachment after rewetting

The individuals attached to plates that survived the air exposure period and detached during rewetting were assumed to be released into the recipient environment. The fraction of releases into the recipient environment throughout the experiments was on average $14.7 \%$ and ranged between 7.9 and $21.8 \%$ (Fig. 4). No significant effect of material was found $(z$-value $=0.52$, $P=0.60)$. Additionally, no significant difference between the quagga and zebra mussel was found ( $z-$ value $=-0.68, P=0.50)$. However, releases into the recipient environment decreased significantly with the increase in air exposure duration $(z$-value $=-3.55$, $P<0.001)$. There were no significant interactions (Fig. 4). Of all, detached individuals during rewetting

Table 1 GLM results of the attachment experiment and the alive detachment during rewetting experiment-dependent variables are species, material and treatment

\begin{tabular}{lcccr}
\hline Source & Estimate & SE & $z$-value & $P$ value \\
\hline Attachment fraction & & & & \\
Intercept & -0.353 & 0.084 & -4.19 & $<0.001$ \\
Species & 1.083 & 0.123 & 8.80 & $<0.001$ \\
Material & 0.656 & 0.109 & 6.00 & $<0.001$ \\
AIC: 427.62 & & & & \\
Alive detached during rewetting & & \\
Intercept & -1.442 & 0.193 & -7.48 & $<0.001$ \\
Species & -0.135 & 0.200 & -0.68 & 0.498 \\
Treatment & -0.711 & 0.200 & -3.55 & $<0.001$ \\
Material & 0.103 & 0.199 & 0.52 & 0.604 \\
AIC: 122.09 & & & & \\
\hline
\end{tabular}




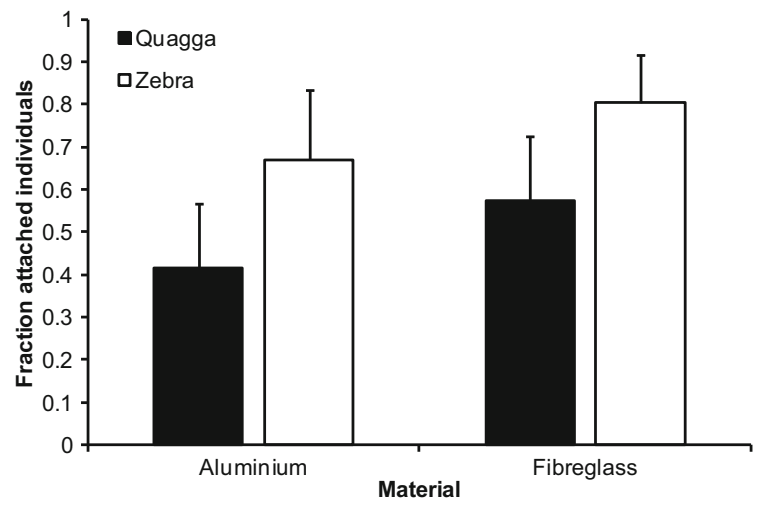

Fig. 3 Fraction of attached individuals quagga and zebra mussels on aluminium and fibreglass. The error bars represent the standard deviation for each treatment

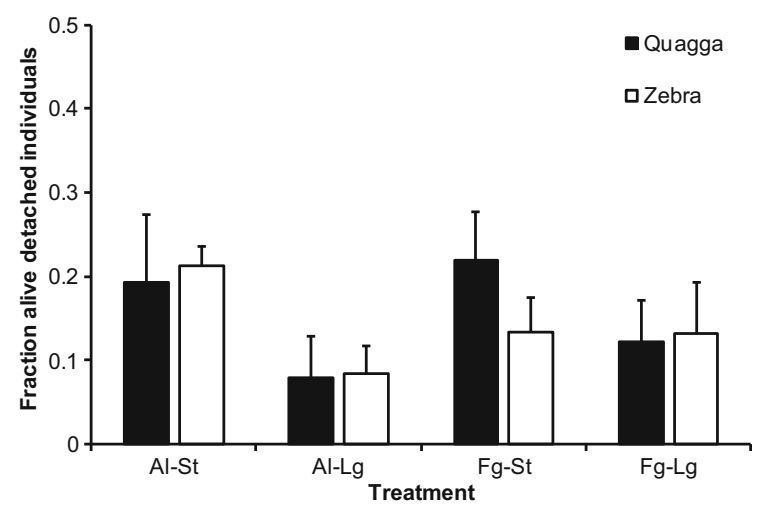

Fig. 4 Fraction of alive detached individuals of quagga and zebra mussels and the standard deviation per treatment. Treatment abbreviations are a combination of material type $(\mathrm{Al}=$ aluminium $; \mathrm{Fg}=$ fibreglass $)$ and overland transport duration $(\mathrm{St}=24 \mathrm{~h} ; \mathrm{Lg}=48 \mathrm{~h})$

on average 58 and $66 \%$ of quaqqa and zebra mussels were alive, respectively.

\section{Discussion}

Our results indicate that zebra mussels are more likely to attach to common boat hull materials than quagga mussels. The higher byssal thread synthesis rate and attachment force of zebra mussels found by Peyer et al. (2009) are a possible explanation for this difference in attachment behaviour. However, Grutters et al. (2012) found no difference in byssal synthesis between quagga and zebra mussels at temperatures lower than $25^{\circ} \mathrm{C}$. Despite the current dominance of the quagga mussel in the Great Lakes, relatively more zebra mussels were found on the hulls of resident boats than quagga mussels (Karatayev et al., 2013). These field observations confirm the experimentally derived higher attachment fraction of zebra mussels compared to quagga mussels. The attachment of mussels in our experiments might be negatively affected by the zinc-coated materials. Zinc is a known dreissenid toxin (Kraak et al., 1994; Dormon et al., 1996). However, a flow through system was used and strong dilution of dissolved zinc limited potential impact of this toxic metal.

Previous research on preference of attachment to various materials showed no difference in attachment between fibreglass and aluminium for both the quagga (Mueting et al., 2010) and zebra mussel (Marsden \& Lansky, 2000). In our study, both species attached more to fibreglass than to aluminium. Mueting et al. (2010) and Marsden \& Lansky (2000) looked at the attachment preference of larvae, whereas in the presented experiment adult individuals were used. Thus, there appears to be an attachment preference difference between adults and larvae for both quagga and zebra mussels.

A relatively high percentage of attached individuals survived the air exposure and subsequently detached alive after rewetting. These results confirm that boat hull-mediated overland dispersal is a potential pathway for dreissenid releases into hydrologically isolated water bodies. Since the average proportion of alive detachment was $14.7 \%$, the release potential of recreational boats fouled by dreissenids is high. The actual release potential is even larger due to the result that $80 \%$ of all individuals that remained attached during the $48 \mathrm{~h}$ of rewetting survived the air exposure. Moreover, the used individuals were sexually mature (maturity is reached at 5-12 mm; reviewed in Nichols 1996); thus, individuals that remained attached might be able to spawn when the boat is left in the water for a considerable amount of time. Their spat may subsequently establish viable populations. Therefore, further research on effects of air exposure on the release of spat is recommended.

The experiments were performed under ideal laboratory conditions without including additional factors that may influence air exposure survival in nature. For instance, attached individuals were equally distributed on the plates, whereas under natural conditions individuals will likely cluster together. 
Air exposure survival of clustered individuals, during subfreezing temperatures, is higher compared to loosely aggregated individuals (McMahon et al., 1993). Moreover, air exposure survival depends on temperature, duration and relative humidity (McMahon et al., 1993; Ricciardi et al., 1995; Tucker et al., 1997; Paukstis et al., 1999; Collas et al., 2014). Thus, the fraction of individuals released into a recipient environment will vary with temperature and relative humidity conditions. The attachment strength of the experimental mussels might not mimic natural attachment strengths, limiting the detachment results. Moreover, during overland transport air flow, shaking and vibration of ships may affect the number of mussels that attach, survive air exposure and, subsequently, detach during rewetting. Especially the launch of a boat into water produces strong mechanical forces that would result in a higher dislodgement of loosely attached individuals, increasing the release of dreissenids into the recipient environment. Further research is recommended on the effect of these factors.

No difference in the percentage of detached mussels that were alive after rewetting was found between quagga and zebra mussels. This is likely due to a combination of different mechanisms that countervail. Zebra mussels have a higher attachment force, measured as the minimum force needed to detach an individual, than quagga mussels (Peyer et al., 2009). The higher attachment force of the zebra mussel results in a lower probability of detachment compared to the quagga mussel. However, the air exposure tolerance of quagga mussels is lower than that of zebra mussel (Ricciardi et al., 1995), thereby decreasing the chance of alive quagga mussel detachment. Of all detached individuals during rewetting, more zebra mussels were alive than quagga mussels, supporting the difference in air exposure tolerance between the species. The importance of air exposure tolerance as the main factor determining alive detachment is supported by the significantly lower alive detachment with increasing air exposure duration (e.g., overland transport). Although, further research is required on the development of attachment force of dreissenids during air exposure and subsequent rewetting.

There is increasing evidence that the propagule pressure of alien species aids their establishment (Lockwood et al., 2005; Colautti et al., 2006; Simberloff, 2009). The experimentally derived magnitude of release into a recipient environment can be used to estimate the dreissenid propagule pressure of trailered boats. In order to do so, data are needed on dreissenid densities on boat hulls. Additionally, information is required on the fraction of boats that are fouled in the source water and, as not all boats move to uninfested lakes, the fraction of boats that move to uninfested lakes within two days of air exposure. If the propagule pressure for a single boat is then multiplied by the total amount of boats that moved from the source water, a propagule pressure of trailered boats per year from a specific lake can be calculated. Using boating behaviour data from Lake St. Clair (on average 96,800 boats per year; Johnson et al., 2001) in combination with boat fouling fractions and densities reported by Karatayev et al. (2013), an attempt can be made to estimate the propagule pressure of boats departing from Lake St. Clair. Usage of the average fraction of alive dreissenid detachment during rewetting, $14.7 \%$, and the range of 4 up to 3940 attached dreissenids reported by Karatayev et al. (2013) the yearly propagule pressure of the 96,800 boats departing from Lake St. Clair ranges between 898 and 884,782 dreissenids. The calculated introductions do not take into account that boat hulls are actively cleaned by boat users (Clean Boating Act, 2008), thereby decreasing the propagule pressure. The presented propagule pressure of trailered boats is based on several assumptions due to limited data availability on boating behaviour. Moreover, the propagule pressure estimation is inherently limited to the experimental conditions mimicking release into a recipient environment. However, our estimation indicates that it is feasible to calculate the propagule pressure of overland transport via boat hulls in case sufficient data is available on the pathway, number of vectors and boat fouling by mussels.

The results support that dreissenids can disperse long distances into isolated lakes via the boat hullmediated introduction pathway. This is in accordance with the recorded dispersal of zebra mussels via several long-distance jumps (Wilson et al., 1999) and the reported dispersal via recreational boats in Ireland (Minchin et al., 2003) and Switzerland (De Ventura et al., 2016). The possibility to disperse implies that legislative regulation to clean, drain and dry boats (e.g., Clean Boating Act, 2008) and educational campaigns to stop the spread of dreissenids via boats hulls are important management tools to decrease the release of dreissenids into uninfested lakes. Moreover, 
the instalment of cleaning equipment near popular boating areas might be important. More quantitative data is needed on boat movement and the density of attached individuals to successfully incorporate the estimated number of release into recipient environments in invasion risk models.

Acknowledgements This paper has been presented by FPL Collas at the 2nd International Meeting on Biology and Conservation of Freshwater Bivalves in Buffalo (USA, NY), October 4-8, 2015. The authors would like to thank Knut Mehler, Mark Clapsadl, Joshua Fisher and Kathleen Hastings (Great Lakes Center, SUNY Buffalo State) for their assistance during laboratory and field work, Robert Warren (Biology Department, SUNY Buffalo State) for statistical advises and two anonymous reviewers for their suggestions to improve our manuscript. This research was partly funded by the Radboud Honours Academy of the Radboud University, Nijmegen.

Open Access This article is distributed under the terms of the Creative Commons Attribution 4.0 International License (http:// creativecommons.org/licenses/by/4.0/), which permits unrestricted use, distribution, and reproduction in any medium, provided you give appropriate credit to the original author(s) and the source, provide a link to the Creative Commons license, and indicate if changes were made.

\section{References}

Ackerman, J. D., C. R. Ethier, D. G. Allen \& J. K. Spelt, 1992. Investigation of zebra mussel adhesion strength using rotating disks. Journal of Environmental Engineering 188: 708-724.

Ackerman, J. D., C. M. Cottrell, C. R. Ethier, D. G. Allen \& J. K. Spelt, 1995. A wall jet to measure the attachment strength of zebra mussels. Canadian Journal of Fisheries and Aquatic Sciences 52: 126-135.

Buchan, L. A. J. \& D. K. Padilla, 1999. Estimating the probability of long-distance overland dispersal of invading aquatic species. Ecological Applications 9: 254-265.

Burlakova, L. E., B. L. Tulumello, A. Y. Karatayev, R. A. Krebs, D. W. Schloesser, W. L. Paterson, T. A. Griffith, M. W. Scott, T. Crail \& D. T. Zanatta, 2014. Competitive replacement of invasive congeners may relax impact on native species: interactions among zebra, quagga and native unionid mussels. PLoS ONE. doi:10.1371/journal. pone. 0114926 .

Colautti, R. I., I. A. Grigorovich \& H. J. MacIsaac, 2006. Propagule pressure: a null model for biological invasions. Biological Invasions 8: 1023-1037.

Collas, F. P. L., K. R. Koopman, A. J. Hendriks, G. van der Velde, L. N. H. Verbrugge \& R. S. E. W. Leuven, 2014. Effects of desiccation on native and non-native molluscs in rivers. Freshwater Biology 59: 41-55.

Clean Boating Act, 2008. Pub. L. 110-288. 122 Stat. 2650-2653. 29 July 2008. United States Environmental Protection
Agency: Clean Boating Act (CBA): Homepage. Website 22 October. 2015.

De Ventura, L., N. Weissert, R. Tobias, K. Kopp \& J. Jokela, 2016. Overland transport of recreational boats as a spreading vector of zebra mussel Dreissena polymorpha. Biological Invasions 18: 1451-1466.

Dormon, J. M., C. M. Cottrell, D. G. Allen, J. D. Ackerman \& J. Spelt, 1996. Copper and copper-nickel alloys as zebra mussel antifoulants. Journal of Environmental Engineering 122: 276-283.

Grutters, B. M. C., M. J. J. M. Verhofstad, G. van der Velde, S. Rajagopal \& R. S. E. W. Leuven, 2012. A comparative study of byssogenesis on zebra and quagga mussels: the effects of water temperature, salinity and light-dark cycle. Biofouling 28: 121-129.

Johnson, L. E. \& J. T. Carlton, 1996. Post-establishment spread in large-scale invasions: the dispersal mechanisms of the zebra mussel Dreissena polymorpha. Ecology 77: 1686-1690.

Johnson, L. E., A. Ricciardi \& J. T. Carlton, 2001. Overland dispersal of aquatic invasive species: a risk assessment of transient recreational boating. Ecological applications 11: 1789-1799.

Karatayev, A. Y., D. K. Padilla, D. Minchin, D. Boltovskoy \& L. E. Burlakova, 2007. Changes in global economies and trade: the potential spread of exotic freshwater bivalves. Biological Invasions 9: 161-180.

Karatayev, V. A., A. Y. Karatayev, L. E. Burlakova \& D. K. Padilla, 2013. Lakewide dominance does not predict the potential for spread of dreissenids. Journal of Great Lakes Research 39: 622-629.

Kavouras, J. H. \& J. S. Maki, 2003. Effects of biofilms on zebra mussel postveliger attachment to artificial surfaces. Invertebrate Biology 122: 138-151.

Kobak, J., 2001. Light, gravity and conspecifics as cues to site selection and attachment behaviour of juvenile and adult Dreissena polymorpha Pallas, 1771. Journal of Molluscan Studies 67: 183-189.

Kobak, J., 2004. Recruitment and small-scale spatial distribution of Dreissena polymorpha (Bivalvia) on artificial materials. Archiv für Hydrobiologie 160: 25-44.

Kobak, J., 2013. Behavior of juvenile and adult zebra mussels (Dreissena polymorpha). In Nalepa, T. F. \& D. W. Schloesser (eds), Quagga and Zebra Mussels: Biology, Impacts, and Control. 2nd edn. CRC Press, Taylor \& Francis Group, Boca Raton: 331-344.

Kobak, J. \& T. Kakareko, 2009. Attachment strength, aggregation and movement of the zebra mussel (Dreissena polymorpha, Bivalvia) in the presence of potential predators. Archiv für Hydrobiologie 174: 193-204.

Kobak, J., M. Poznańska \& T. Kakareko, 2009. Effect of attachment status and aggregation on the behaviour of the zebra mussel Dreissena polymorpha. Journal of Molluscan Studies 75: 119-126.

Kobak, J., T. Kakareko \& M. Poznańska, 2010. Changes in attachment strength and aggregation of zebra mussel, Dreissena polymorpha in the presence of potential fish predators of various species and size. Hydrobiologia 644: 195-206.

Kraak, M. H. S., D. Lavy, H. Schoon, M. Toussaint, W. H. M. Peeters \& N. van Straalen, 1994. Ecotoxicity of mixtures of 
metals to the zebra mussel Dreissena polymorpha. Environmental Toxicology and Chemistry 13: 109-114.

Lockwood, J. L., P. Cassey \& T. Blackburn, 2005. The role of propagule pressure in explaining species invasions. Trends in Ecology \& Evolution 20: 223-228.

Marsden, J. E. \& D. M. Lansky, 2000. Substrate selection by settling zebra mussels, Dreissena polymorpha, relative to material, texture, orientation, and sunlight. Canadian Journal of Zoology 78: 787-793.

Matthews, J., G. Van der Velde, A. Bij de Vaate, F. P. L. Collas, K. R. Koopman \& R. S. E. W. Leuven, 2014. Rapid range expansion of the invasive quagga mussel in relation to zebra mussel presence in The Netherlands and Western Europe. Biological Invasions 16: 23-42.

McMahon, R. F., T. A. Ussery \& M. Clarke, 1993. Use of emersion as a zebra mussel control method. U.S. Army Corps of Engineers technical report, Viskburg, No. EL-931.

Minchin, D., M. Caitríona \& R. Rosell, 2003. The zebra mussel (Dreissena polymorpha Pallas) invades Ireland: human mediated vectors and the potential for rapid intranational dispersal. Biology and Environment: Proceedings of the Royal Irish Academy 103: 23-30.

Mueting, S. A., S. L. Gerstenberger \& W. Hing Wong, 2010. An evaluation of artificial substrates for monitoring the quagga mussel (Dreissena bugensis) in Lake Mead, Nevada-Arizona. Lake and Reservoir Management 26: 283-292.

Nichols, S. J., 1996. Variations in the reproductive cycle of Dreissena polymorphain Europe, Russia, and North America. American Zoologist 36: 311-325.

Oreska, M. P. J. \& D. C. Aldridge, 2011. Estimating the financial costs of freshwater invasive species in Great Britain: a standardized approach to invasive species costing. Biological Invasions 13: 305-319.

Paukstis, G. L., J. K. Tucker, A. M. Bronikowski \& F. J. Janzen, 1999. Survivorship of aerially-exposed zebra mussels (Dreissena polymorpha) under laboratory conditions. Journal of Freshwater Ecology 14: 511-517.

Peyer, S. M., A. J. McCarthy \& C. E. Lee, 2009. Zebra mussels anchor byssal threads faster and tighter than quagga mussels in flow. Journal of Experimental Biology 212: 2027-2036.

Pimentel, D., R. Zuniga \& D. Morrison, 2005. Update on the environmental and economic costs associated with alieninvasive species in the United States. Ecological Economics 52: 273-288.

Pollux, B., D. Minchin, G. van der Velde, T. van Alen, S. Yeo, M. van der Staay \& J. Hackstein, 2003. Zebra mussels (Dreissena polymorpha) in Ireland, AFLP-fingerprinting and boat traffic both indicate an origin from Britain. Freshwater Biology 48: 1127-1139.

R Development Core Team, 2008. R: a language and environment for statistical computing. R Foundation for Statistical Computing, Vienna.

Ricciardi, A., R. Serrouya \& F. G. Whoriskey, 1995. Aerial exposure tolerance of zebra and quagga mussels (Bivalvia: Dreissenidae): implications for overland dispersal. Canadian Journal of Fisheries and Aquatic Sciences 52: 470-477.

Simberloff, D., 2009. The role of propagule pressure in biological invasions. Annual Review of Ecology, Evolution, and Systematics 40: 81-102.

Tucker, J. K., C. H. Theiling, F. J. Janzen \& G. L. Paukstis, 1997. Sensitivity to aerial exposure: potential of systemwide drawdowns to manage zebra mussels in the Missisippi River. Regulated Rivers: Research \& Management 13: 479-487.

Ussery, T. A. \& R. F. McMahon, 1995. Comparative study of the desiccation resistance of zebra mussels (Dreissena polymorpha) and quagga mussels (Dreissena bugensis). Technical Report EL-95-6. US Army Corps of Engineers, Vicksburg.

Ward, J. M. \& A. Ricciardi, 2007. Impacts of Dreissena invasions on benthic macroinvertebrate communities: a metaanalysis. Diversity and Distributions 13: 155-165.

Wilson, A. B., K. A. Naish \& E. G. Boulding, 1999. Multiple dispersal strategies of the invasive quagga mussel (Dreissena bugensis) as revealed by microsatellite analysis. Canadian Journal of Fisheries and Aquatic Sciences 56: 2248-2261. 